\title{
The effects of propofol and midazolam on rat spermatogenic parameters
}

[Efeitos do propofol e midazolam em parâmetros espermatogênicos em ratos]

\author{
S. Celaleddin 1, K. Volkan ${ }^{2 *}$
}

${ }^{1}$ Department of Anaesthesiology and Reanimation - Yuzuncu Yil University - School of Medicine - Van, Turkey ${ }^{2}$ Department of Artificial Insemination - Van Yuzuncu Yil University - Veterinary Faculty - Van, Turkey

\begin{abstract}
There is a need for various anesthetic agents to obtain sperm in the field of human and veterinary medicine. Propofol and midazolam are among the most preferred among these agents. The aim of this study was to determine how sperm paramaters are affected according to the anesthetic agent used. Propofol $(2 \mathrm{mg} / \mathrm{kg})$ and midazolam $(3,5-7,5 \mathrm{mg} / \mathrm{kg}$ ) were administered twice a day (morning-evening) for one week. As a result of this study, there was no statistical difference in sperm density and abnormal sperm rates (respectively $\mathrm{P}=0,673, \mathrm{P}=0,479$ ). Sperm motility rates are similar in the control and propofol groups, while the motility rate in the midazolam group is statistically lower. (Control group \%85 - Midazolam group \%68.75Propofol group \%83.75), $(\mathrm{P}<0.05)$. As a result of this study, the confidence interval of propofol was higher than the other anesthetic agents used for sperm retrieval.
\end{abstract}

Keywords: propofol, midazolam, sperm

\section{RESUMO}

São necessários vários agentes anestésicos para obter espermatozoides no campo da medicina humana e veterinária. Propofol e midazolam estão entre os agentes preferidos. O objetivo deste estudo foi determinar como os parâmetros de esperma são afetados de acordo com o agente anestésico utilizado. Propofol ( $2 \mathrm{mg}$ $/ \mathrm{kg}$ ) e midazolam $(3,5-7,5 \mathrm{mg} / \mathrm{kg}$ ) foram administrados duas vezes ao dia (manhã e noite) durante uma semana. Neste estudo, não houve diferença estatística na densidade espermática e nas taxas anormais de espermatozoides (respectivamente $P=0,673, P=0,479$ ). As taxas de motilidade espermática são semelhantes nos grupos controle e propofol, enquanto a taxa de motilidade no grupo midazolam é estatisticamente menor. (Grupo controle \% 85 - grupo midazolam \% 68,75 - grupo propofol \% 83,75), (P $<0,05)$. Neste estudo, o intervalo de confiança do propofol foi maior do que os outros agentes anestésicos utilizados na recuperação espermática.

Palavras-chave: propofol, midazolam, esperma

\section{INTRODUCTION}

Anesthetics are chemical agents used for the prevention of pre and postoperative pain as well as for the production of sperm and oocytes in the living creatures with an infertility problem. There is a need for anesthetics in all methods used for sperm collection, including percutaneous epididymal sperm aspiration (PESA), percutaneous testicular sperm aspiration (PTSA), testicular sperm extraction (TESE), and electroejaculation method used in different animal species. The aim of the study is to determine the effect of Midazolam and Propofol, which are two of the anesthetics used in pre-medication for sperm aspiration, on the sperm parameters.

Sperm examination (also known as spermiogram, semen analysis, or sperm analysis) is a test performed to evaluate the amount, color, odor, count, morphology, mobility, dead-live ratio, and abnormalities of sperm. The World Health Organization (WHO) continues its standardization efforts to evaluate the fertility

Recebido em 30 de janeiro em 2020

Aceito em 28 de abril de 2020

*Autor para correspondência (corresponding author)

E-mail: volkan_kosal@hotmail.com 
potential of the sperm sample. These standards include macroscopic (volume, color, odor, mass motion) and microscopic (motility, density, abnormal, dead-live) sperm parameters. Any negative results in any of the spermatological characteristics directly affect fertilization (WHO, 1999).

In the fields of both human and veterinary medicine, various anesthetics (ketamine, xylazine, atipamezole, propofol, medetomidine, thiopental, haloten, midazolam) are used in the methods utilized for the sperm collection. In the selection of anesthetics to be used, the following factors are taken into consideration: safety range, toxicity, muscle relaxation, and its effects on the systems (Adams and Pacharinsak, 2015; Sönmez et al., 2018).

Among the anesthetics used in the studies, propofol, of which only $1 \%(10 \mathrm{mg} / \mathrm{mL})$ emulsion is available for intravenous administration, is the most commonly used parenteral anesthetic in the United States of America. Midazolam is the most preferred agent among the benzodiapezines and can be administered via intravenous, oral, and rectal routes. Despite having detailed information on the side effects of anesthetics on the central nervous system, cardiovascular system, muscle system, and psychological effects, there are limited number of studies on its effects on genital system (Reves et al., 1978; Langley and Heel, 1988).

\section{MATERIALS AND METHODS}

This study was conducted at Van Yuzuncu Yil University Animal, Research Ethics Committee (Approval date 30/05/2019, Decision number 2019/05). This study was carried out with Wistar Albino rats. A total of 24 rats were randomly divided into three groups with eight rats in each study group. Group 1 (Control Group) $(n=8)$ : No drug administration was performed in this group. Group 2 (Propofol Group) $(n=8)$ : Rats in this group were given $1 \%$ propofol i.p. (DIPRIVAN ${ }^{\circledR}$ IV Ampoule, Propofol $10 \mathrm{mg} / \mathrm{ml}$ ) with a dose of
$2.5 \mathrm{mg} / \mathrm{kg}$ twice a day (in the morning and in the evening) for seven days. Group 3 (Midazolam Group) $(n=8)$ : Rats in this group were given midazolam i.p. (DEMIZOLAM ${ }^{\circledR}$ IV Ampoule, $5 \mathrm{mg} / \mathrm{ml}$ ) with an average dose of $3.5-7.5 \mathrm{mg} / \mathrm{kg}$ twice a day (in the morning and in the evening) for seven days.

Motility examination: The sperm sample is placed on the glass slide on the heating table set to $38^{\circ} \mathrm{C}$ immediately after epididymis puncture. The coverslip is left at a $45^{\circ}$ angle and the motility is detected via the microscope with a magnification of x40 (in \%) (Hafez and Hafez, 2000). Density analysis: Following the epididymis puncture, sperm samples of $0.1 \mathrm{ml}$ are added to the Eppendorf tubes with $0.5 \mathrm{ml}$ Hayem solution. On the Thomas glass slide, the number of sperm in $1 \mathrm{ml}$ is calculated (Hafez and Hafez, 2000). Abnormal sperm ratio: The sperm obtained via epididymis puncture is taken to Eppendorf tubes with $0.5 \mathrm{ml}$ Hancock solution. At least 400 sperm samples are examined at the magnitude of $\mathrm{x} 40$ to determine the ratio (Hafez and Hafez, 2000).

Statistical Analysis: Before performing the statistical analysis, data were examined with Shapiro-Wilk test for normality and Levene test for homogeneity of variances as parametric test assumptions. One-way ANOVA was used to evaluate the differences between groups for the variables. Tukey's test was used as post hoc test for the variables that were found statistically significant. For all comparisons, differences were considered with a minimum of 0.05 significance level. All statistical analysis was performed by using SPSS 14.01 package program for Windows.

\section{RESULTS}

Between the control group, propofol group and midazolam group there was no statistical difference in sperm density and abnormal sperm rates. Sperm motility rates are similar in the control and propofol groups, while the motility rate in the midazolam group is statistically lower $(\mathrm{P}<0.05)$.

Table 1. Sperm Motility, Sperm Density, Abnormal Spermatozoa Rate

\begin{tabular}{lccc}
\multicolumn{1}{c}{ Group } & Motility $(\%)$ & Density $(\mathrm{x} 109 / \mathrm{ml})$ & Abnormal sperm $(\%)$ \\
\hline Control & $85 \pm 7.56^{\mathrm{a}}$ & $2.35 \pm 0.13$ & $24.63 \pm 2.20$ \\
Propofol & $83.75 \pm 7.44^{\mathrm{a}}$ & $2.38 \pm 0.31$ & $26.50 \pm 3.74$ \\
Midazolam & $68.75 \pm 8.35^{\mathrm{b}}$ & $2.40 \pm 0.46$ & $25.25 \pm 3.85$ \\
\hline
\end{tabular}

a,b: different letters in the same column show statistical difference $(\mathrm{P}<0.05)$. 


\section{DISCUSSION}

In order to determine the effects of anesthetics, their effects on the reproductive system have begun to be investigated in studies using many anesthetics on different animal species. Their effects on motility and density parameters have been currently pointed out in recent studies. In a study by Batista et al. (2016) on dogs, thiopental, propofol and ketamine were used, and thiopental was reported to have a negative effect on motility rate. Our results were similar to this study. While there was no negative effect in the propofol group, midazolam was found to adversely affect the motility.

Oropeza-Hernandez et al. (2002) reported that sperm motility decreased after 45 days in rats that were kept under control for 60 days. Considering the mode of administration, difference of anesthetic agents, and application time, midazolam was observed to have negative effects on motility rates within seven days and our results were found to be in parallel with this study.

In a study in which ethyl ether was used in inhalation anesthesia, rats were exposed to ethyl ether for 60 days as of their date of birth. Sperm density was reported to decrease in sperm samples taken from the rats. In the present study, no effect on sperm density was determined. Since spermatogenesis lasts about 45-50 days in rats, it may be thought that it is associated with the time of exposure to the anesthetic agent (Arena and Pereira, 2002).

In a study by Souza et al. (2009), sperm samples were taken via Tiletamine-Zolazepam combination and propofol administration in pecari (Tayassu tajacu), and sperm density and motility were reported to decrease in the group, which was administered Tiletamine-Zolazepam. Although sperm can be taken from several animal species (rams, goats, turtle, iguana, snake) through electroejaculation method under anesthesia, there are difficulties while taking sperm from reptiles under normal conditions. Therefore, it is not possible to compare sperm parameters with normal values (Zimmerman and Mitchell, 2017).

In a study involving pecari (Tayassu tajacu) carried out in the United States of America, sperm samples were taken through electroejaculation method by using different anesthetic agents (atipamezole, medetomidine) and the sperm density was observed to be higher in the group that received atipamezole than the group that received medetomidine. In our study the difference may be attributed to the selection of different sperm collection methods and anesthetic agents (Paiva et al., 2014).

In a study of goats under anesthesia and sedation (ketamine + xylazine), the motility rate in the anesthesia group was found to be higher. The results of this study were found to be similar with our results (Abril-Sanchez et al., 2018). Although the anesthetics used were different, the motility rate was lower in the midazolam group than the propofol group.

\section{CONCLUSION}

Sperm parameters of the animals under anesthesia vary according to the type of anesthetics used, exposure time to anesthetics, and methods used for the sperm collection. In the literature, propofol has been reported to provide better results compared to other anesthetics and to have no negative effect on sperm parameters. Further studies should be carried out to investigate the effects of anesthetic agents on the reproduction system.

\section{REFERENCES}

ABRIL-SÁNCHEZ, S.; CROSIGNANI, N.; FREITAS-DE-MELO, A. et al. Sedation or anaesthesia decrease the stress response to electroejaculation and improve the quality of the collected semen in goat bucks. Animals, v.12, p.2598-2608, 2018.

ADAMS, S.; PACHARINSAK, C. Mouse anesthesia and analgesia. Mouse Biol., v.5, p.5163, 2015.

ARENA, A.C.; PEREIRA, O.C.M. Neonatal inhalatory anesthetic exposure: reproductive changes in male rats. Comp. Biochem. Physiol.. v.133, p.633-640, 2002.

BATISTA, M.; VILAR, J.; ROSARI, I.; TERRADAS, E. Influence of different anaesthetic protocols over the sperm quality on the fresh, chilled $\left(4^{\circ} \mathrm{C}\right)$ and frozen- thawed epididymal sperm samples in domestic dogs. Reprod. Domest. Anim., v.51, p.758-765, 2016. 
HAFEZ, B.; HAFEZ, E.S.E. Reproduction in farm animals. 7.ed. Philadelphia: Lippincott Williams and Wilkins; 2000. 509p.

LANGLEY, M.S.; HEEL, R.C. Propofol. A review of its pharmacodynamic and pharmacokinetic properties and use as an inravenous anaesthetic. Drugs, v.35, p.334-372, 1988.

OROPEZA-HERNANDEZA,

L.F.; QUINTANILLA-VEGAA, B.; ALBORESA, A.; FERNANDEZ-GUASTIB, A. Inhibitory action of halothane on rat masculine sexual behavior and sperm motility. Pharmacol. Biochem. Behav., v.72, p.937-942, 2002.

PAIVA, A.L.C.; NUNES, T.L.; OLIVERIA, M.G.C. et al. Effect of atipamezole and medetomidine administration on seminal variebles and functions of erection and ejaculation of the collared pecary (Tayassu tajacu) after electroejaculation. BMC Vet. Res., v.10, p.170176, 2014.

REVES, J.G.; LELL, W.A.; MCMCRACKEN, L.E.; KRAVETS, R.A.; PROUGH, D.S. Comparasion of morphine and ketamine anesthetic technics for coronary surgery. South Med. J., v.71, p.33-36, 1978.
SÖNMEZ, M.; ACISU, T.C.; KOCA, R.H. Semen collection methods and spermatological reference values in farm animals. Turk. Klinik. J. Reprod. Artif. Insemin-Special Top., v.4, p.1-17, 2018.

SOUZA, A.L.P.; CASTELO, T.S.; QUEIROZ, J.P.A.F. et al. Evaluation of anesthetic protocol for the collection of semen from captive collared peccaries (Tayassu tajacu) by electroejaculation. Anim. Reprod. Sci., v.116, p.370-375, 2009.

WHO laboratory manual fort he examination of human semen and sperm-cervical mucus interaction. 4.ed. Cambridge: Cambridge University Press. 1999.

ZIMMERMAN, D.M.; MITCHELL, M.A. Semen collection and ejaculate characteristics of the Leopard Tortoise (Stigmochelys pardalis). Conserv. Physiol. v.5, p.1-9, 2017. 